\title{
Enhancement of polar phase of PVDF by forming PVDF/SiC nanowire composite
}

\author{
Jie-Fang Huang, Song-Jia Han, Hui-Jiuan Chen, Gui-Shi Liu, Gong-Tan Li, Yu-Cheng Wang, \\ Zi-Xin Wang*, Bo-Ru Yang ${ }^{\star}$
}

The State Key Laboratory of Optoelectronic Materials and Technologies, School of Electronics and Information Technology, and SYSU-CMU Shunde International Joint Research Institute, Sun Yat-Sen University, Guangzhou, 510006, China

*E-mail: wangzix@mail.sysu.edu.cn, paulyang68@icloud.com

Zhen-Hua Luo

School of Water, Energy and Environment, Cranfield University, Cranfield, Bedforshire, MK43 0AL, UK

\author{
and Han-Ping D. Shieh
}

The Department of Photonics and Display Institute, National Chiao Tung University, Hsinchu, 300, Taiwan

\begin{abstract}
Different contents of silicon carbide ( $\mathrm{SiC}$ ) nanowires were mixed with Poly(vinylidene fluoride) (PVDF) to facilitate the polar phase crystallization. It was shown that the annealing temperature and $\mathrm{SiC}$ content affected the phase and crystalline structures of $\mathrm{PVDF} / \mathrm{SiC}$ samples. Furthermore, the addition of $\mathrm{SiC}$ nanowire enhanced the transformation of non-polar $\alpha$ phase to polar phases and increased the relative fraction of $\beta$ phase in PVDF. Due to the nucleating agent mechanism of $\mathrm{SiC}$ nanowires, the interfacial interaction between the negatively charged surface of $\mathrm{SiC}$ nanowires and the positively charged $\mathrm{CH}_{2}$ groups of $\mathrm{PVDF}$ facilitated the formation of polar phases in PVDF.
\end{abstract}

Index Terms - Poly(vinylidene fluoride); silicon carbide nanowires; polar phase; annealing temperature; content.

\section{INTRODUCTION}

PIEZOELECTRIC materials are commonly used for pressure sensing [1-2], energy harvesting [3], health monitoring [4-5], etc. Comparing to piezoelectric crystals and piezoelectric ceramics, piezoelectric polymers are considered as the ideal materials for wearable pressure sensor devices, owing to their high dielectric constant, flexibility, and biocompatibility. Among all the piezoelectric polymers, Polyvinylidene fluoride (PVDF) is one of the most investigated materials. The structure of PVDF molecules is a macromolecular chain, which consists of repeated units of $\mathrm{CH}_{2}$ groups and $\mathrm{CF}_{2}$ groups. It is a semi-crystalline polymershowing complex polycrystalline structures and can be divided into five crystalline phases: $\alpha, \beta, \gamma, \delta$, and $\varepsilon$ phases, which are related to different chain conformations [6-7]. The $\alpha$ phase is the most common crystalline phase and its main chain conformation presents as TGTG' (trans-gauche-trans-gauche) structure. The dipole moments of $\alpha-\mathrm{PVDF}$ are reversely arranged in order, showing no piezoelectricity. The PVDF film fabricated by slowly cooling from melt or solution casting will mostly contributes to $\alpha$ phase [8-9]. The $\alpha$ phase of PVDF can transform into $\delta$ phase by poling the material in strong electric field to obtain feeble piezoelectricity. In the $\beta$ phase of PVDF, the polymer chains have the all-trans (TTTT) planar zigzag conformation, in which hydrogen atoms and fluorine atoms are arranged on the opposite sides of the main chain, respectively. As for the $\beta$ phase of PVDF, dipole moments point in the same direction, showing the strongest piezoelectricity. The $\gamma$ phase of PVDF is formed from melting crystallization at high temperature (about $170^{\circ} \mathrm{C}$ ) [10]. The $\gamma$ and $\varepsilon$ phases, with the main chain conformation of $\mathrm{T}_{3} \mathrm{GT}_{3} \mathrm{G}$, have weaker piezoelectricity in comparison with $\beta$ phase, due to the $\mathrm{T}-\mathrm{G}$ bond which presents at every third repeated T-T bond. Among these five phases, the non-polar $\alpha$ phase and the polar phases ( $\beta$ and $\gamma$ phases) of PVDF are the most investigated.

Many treatments have effects on the crystalline structures of PVDF, including mechanical stretching [11], heat treatment [12], electric field poling [13], electrospinning [14], [15], solvents species [16]. In recent years, some research works indicate that mixing PVDF with nano-fillers facilitates the formation of $\beta$ phase in PVDF and improves its piezoelectricity. Indolia and Gaur added various contents of $\mathrm{ZnO}$ nanoparticles into PVDF solution to investigate the structural characteristics of PVDF/ZnO [17]. The degree of $\beta$ phase increased when higher $\mathrm{ZnO}$ nanoparticle contents were 
mixed in the PVDF film. Thakur et al. found that the addition of kadinite and halloysite induced the transformation of $\alpha$ phase into $\beta$ phase [18]. According to the nucleation mechanism, the interaction between the kadinate/halloysite and the groups of PVDF can enhance the $\beta$ phase crystallinity. Ye et al. incorporated PVDF films with tetradecylphosphonic acid (TDPA)- $\mathrm{BaTiO}_{3}$ [19]. They obtained a high crystallinity of $\beta$ phase PVDF at about $93 \%$ with a TDPA-BaTiO3 nanoparticles content of $20 \%$. Other kinds of nano-fillers such as ferrite nanoparticles [20], gold nanoparticles [21], $\mathrm{TiO}_{2}$ nanoparticles [22], clays [23] have been mixed into PVDF to enhance the piezoelectricity of PVDF film. As a ceramic and semiconductor material, silicon carbide $(\mathrm{SiC})$ exhibits stable chemical properties, high thermal conductivity, small thermal expansion coefficient, and good wear resistance [24]. Mixing ceramic materials with PVDF is a simple way to improve the properties of the polymer [25]. SiC nanoparticle provides much larger length-to-diameter and surface-to-volume ratios than $\mathrm{SiC}$ nanowire and bulk $\mathrm{SiC}$. Although some works have previously investigated the $\mathrm{PVDF} / \mathrm{SiC}$ nanoparticles, mixing PVDF with $\mathrm{SiC}$ nanowires has not been comprehensively investigated and its mechanism is still not fully understood.

In this work, we utilize $\mathrm{SiC}$ nanowires as a nucleating agent to facilitate the transformation of $\alpha$ phase into polar phases, improving the relative fraction of $\beta$ phase in PVDF thin film. Thin films were prepared by solution processing at different ratios of $\mathrm{PVDF} / \mathrm{SiC}$. We investigated the crystalline structures and surface morphology of pure PVDF and PVDF/SiC nanowire composites, which were annealed at different temperatures. The interaction mechanism between PVDF and $\mathrm{SiC}$ nanowires was investigated and explained.

\section{EXPERIMENTAL}

\subsection{MATERIALS}

PVDF $(\mathrm{Mw}=534,000)$ and N,N-dimethylacetamide (DMAc, purity of 99\%) were purchased from Sigma Aldrich (St. Louis, Mo, USA). SiC nanowires (diameter of 100-600 nm, length of about 100 um, purity of $98 \%$ ) were purchased from Xianfeng Nanomaterial Inc (Nanjing, China).

\subsection{PROCESSING}

PVDF powder was dissolved in N,N-dimethylacetamide (DMAc) solvent at the content of $10 \mathrm{wt} \%$ and stirred at room temperature on the magnetic stirrer for four hours until PVDF was completely dissolved. Different weights of $\mathrm{SiC}$ nanowires were added into PVDF solvent at the contents of $0 \mathrm{wt} \%, 2$ $\mathrm{wt} \%, 5 \mathrm{wt} \%$, and $8 \mathrm{wt} \%$, respectively. By stirring at room temperature for over 48 hours and ultra-sonicating for one hour, good dispersion of $\mathrm{SiC}$ in PVDF solution was achieved. The solution of PVDF/SiC was drop-casted on a dry glass, which was cleaned in acetone, alcohol, and de-ionized water for 15 minutes, respectively. The pure PVDF and PVDF/SiC composite samples were annealed on a hot plate at $140^{\circ} \mathrm{C}$ and $80^{\circ} \mathrm{C}$ for 2 hours, respectively, to evaporate DMAc solvent completely, then cooled slowly at the rate of about $1{ }^{\circ} \mathrm{C} / \mathrm{min}$ to room temperature. Pure PVDF and PVDF/SiC composites were crystallized during these annealing processes. The sample films after cooling were peeled off and prepared for the following testing and characterization.

\subsection{CHARACTERIZATION}

In order to identify the polycrystalline structures of pure $\mathrm{PVDF}$ and $\mathrm{PVDF} / \mathrm{SiC}$ composites with different $\mathrm{SiC}$ contents and annealed at different temperatures, optical microscope (OM, AxioCam MRc 5, ZEISS), scanning electron microscope (SEM, Carl Zeiss Microscopy GmbH, SUPRA 60) and atomic force microscope (AFM, NTEGRA Spectra) were used to observe the surface morphology. X-ray diffraction (XRD, Empyrean) and fourier transform infrared spectroscopy (FTIR, EQUINOX 55) were used to analyze the crystalline structures of pure PVDF and PVDF/SiC composite films. Differential scanning calorimetry (DSC, Netzsch 204) was used to measure the overall crystallinity of the PVDF samples. Stylus profiler (Veeco Dektak 150) was used to measure the thickness of the $\mathrm{PVDF} / \mathrm{SiC}$ films. Energy dispersive spectroscope (EDS, X-Max ${ }^{\mathrm{N}}$, Oxford Instrument) was used to detect the chemical element contents in $\mathrm{SiC}$ nanowires, and a multi-parameter tester (S470-USP/EP SevenExcellence ${ }^{\mathrm{TM}}$ $\mathrm{pH} /$ Conductivity Meter Kit, Mettler Toledo) was used to measure the acid-base property of DMAc solvent.

\section{RESULTS}

\subsection{CRYSTALLINE STRUCTURES AND SURFACE MORPHOLOGY OF PURE PVDF ANNEALED AT 140 ${ }^{\circ} \mathrm{C}$ AND $80^{\circ} \mathrm{C}$}

Annealing temperature has influence on the crystalline phase of PVDF. Figure 1 shows the XRD patterns of pure PVDF annealed at $140^{\circ} \mathrm{C}$ and $80^{\circ} \mathrm{C}$. When the pure PVDF film was annealed at $140^{\circ} \mathrm{C}$, the crystalline phase of pure PVDF was mainly $\alpha$ phase. The diffraction peaks at $17.7^{\circ}, 18.3^{\circ}$, $19.9^{\circ}$, and $26.6^{\circ}$ correspond to the $\alpha$ phase at the (100), (020), (110), and (021) planes of the $\alpha$ phase of PVDF, respectively [26-27]. When the pure PVDF was annealed at $80^{\circ} \mathrm{C}$, the $\beta$ phase of PVDF with the diffraction peak of $20.3^{\circ}$ and $\gamma$ phase of PVDF with the diffraction peak of $18.7^{\circ}$ were observed in the XRD pattern [26]. From the FT-IR spectra shown in Figure $1 \mathrm{~b}$, the characteristic bands at 1180 and $880 \mathrm{~cm}^{-1}$ are assigned to the vibration of carbon-carbon skeleton, $1402 \mathrm{~cm}^{-1}$ corresponds to the swing vibration of $\mathrm{CH}_{2}$, and $1170 \mathrm{~cm}^{-1}$ is related to the stretching vibration of $\mathrm{CF}_{2}$ [28-29]. The characteristic bands at $764,795,855,976,1147,1210$, and $1383 \mathrm{~cm}^{-1}$ correspond to $\alpha$ phase of PVDF [26-27, 30]. Although a weak characteristic band of $840 \mathrm{~cm}^{-1}$ presented in the pure PVDF treated at $140^{\circ} \mathrm{C}$, most of the characteristic bands were related to $\alpha$ phase. This coincided with the XRD result. It confirmed that the domain crystalline form of pure PVDF annealed at $140^{\circ} \mathrm{C}$ was $\alpha$ phase. Whereas at $80^{\circ} \mathrm{C}$, the absorption band of $\beta$ phase at $840 \mathrm{~cm}^{-1}$ and absorption band of $\gamma$ phase at $1234 \mathrm{~cm}^{-1}$ were clearly observed [26-27]. In the 

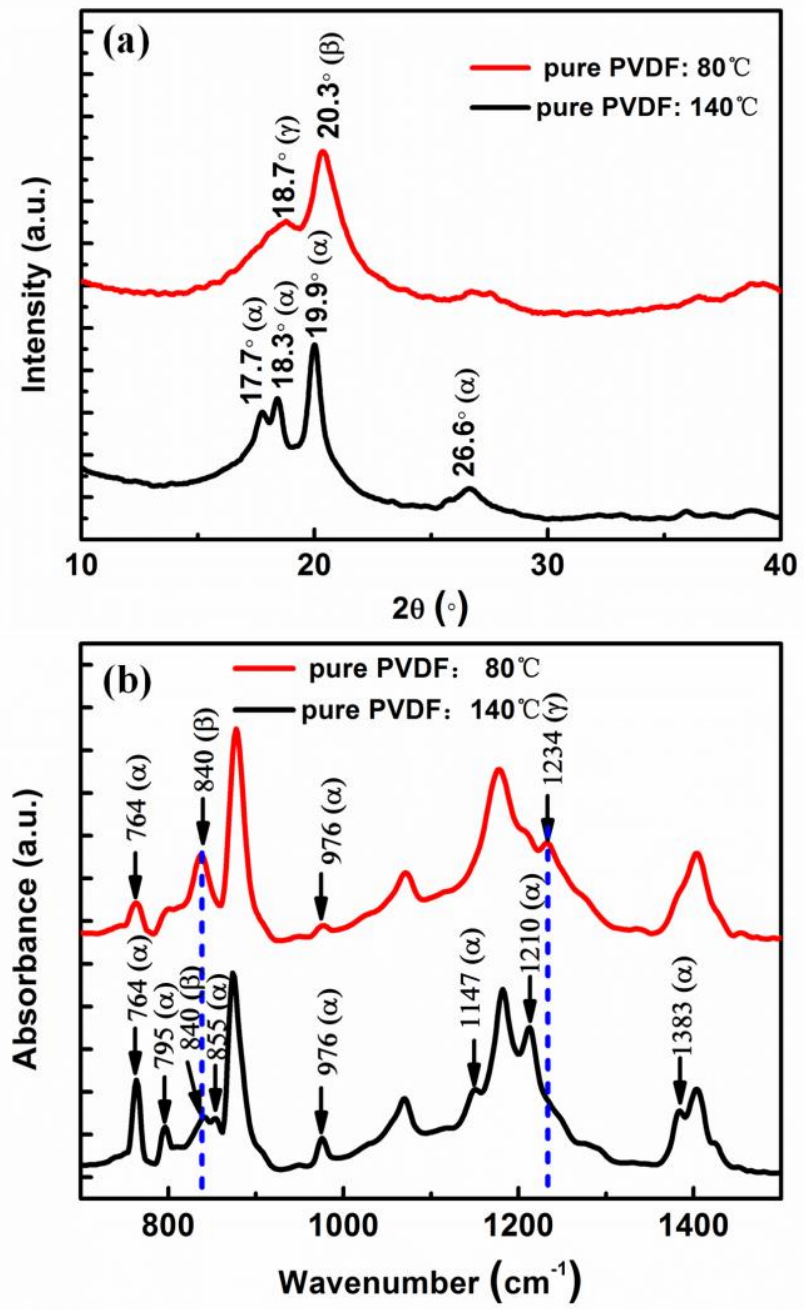

Figure 1. (a) XRD patterns and (b) FT-IR spectra of pure PVDF annealed at $140^{\circ} \mathrm{C}$ and $80^{\circ} \mathrm{C}$

meantime, the intensity of all the characteristic bands corresponding to $\alpha$ phase was less or even not observed. This showed that the dominant crystalline structure were $\beta$ and $\gamma$ phases instead of $\alpha$ phase. Both XRD patterns and FT-IR spectra proved that the annealing temperature has influence on the crystalline phases of PVDF. When the annealing temperature was around $140^{\circ} \mathrm{C}, \mathrm{PVDF}$ was inclined to form non-polar $\alpha$ phase instead of polar $\beta$ phase. This coincides with the explanation from Hsu and Geil [31].

\subsection{SURFACE MORPHOLOGY OF PURE PVDF ANNEALED AT $140^{\circ} \mathrm{C}$ AND $80^{\circ} \mathrm{C}$}

The $\alpha$ and $\beta$ phases of PVDF show different surface morphologies. The SEM and AFM topographic images of pure PVDF further provided evidence of phase transformation between the annealing temperature of $140^{\circ} \mathrm{C}$ and $80^{\circ} \mathrm{C}$. Before the observation of SEM, a thin layer of fine gold was deposited on the surface of the samples to avoid accumulating negative charges. From Figure 2, we observed that the crystalline morphology of PVDF annealed at $140^{\circ} \mathrm{C}$ mostly exhibited the
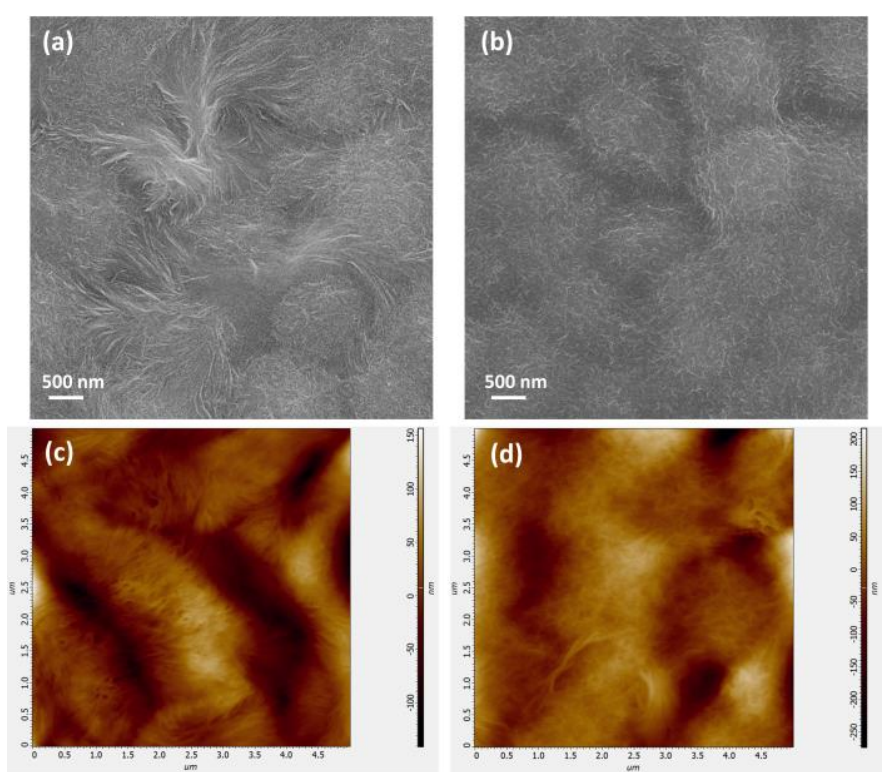

Figure 2. SEM images of pure PVDF annealed at (a) $140^{\circ} \mathrm{C}$ and (b) $80^{\circ} \mathrm{C}$; AFM topographic images of pure PVDF annealed at (c) $140^{\circ} \mathrm{C}$ and (b) $80^{\circ} \mathrm{C}$.

large isotropic spherulite structure, which indicated the dominant crystalline phase was $\alpha$ phase $[25,32]$. The surface of PVDF annealed at $80^{\circ} \mathrm{C}$ were mostly covered with the crystallite structure which was related to $\beta$ phase [32]. Furthermore, the AFM topographic image of pure PVDF annealed at $140{ }^{\circ} \mathrm{C}$ exhibited long and thick wool-like structures, whereas the pure PVDF annealed at $80^{\circ} \mathrm{C}$ mostly showed fine fiber-like surface. The AFM result indicated thatthe PVDF sample annealed at $140^{\circ} \mathrm{C}$ has a lower surface roughness $\left(\mathrm{R}_{\mathrm{q}}=36.6 \mathrm{~nm}\right)$, whereas the PVDF sample annealed at $80^{\circ} \mathrm{C}$ has a rougher surface $\left(\mathrm{R}_{\mathrm{q}}=67.9 \mathrm{~nm}\right)$. [The surface roughness of the film was analyzed to quantify the following parameters: RMS $\left(R_{q}\right)$.] Both of the SEM and AFM topographic images revealed that pure PVDF was inclined to form $\alpha$ phase when annealed at $140^{\circ} \mathrm{C}$, and to form $\beta$ phase at $80^{\circ} \mathrm{C}$.

\subsection{CRYSTALLINE STRUCTURE OF PVDF/SIC COMPOSITES ANNEALED AT $140^{\circ} \mathrm{C}$ AND $80^{\circ} \mathrm{C}$}

To investigate the effect of $\mathrm{SiC}$ nanowires on the crystalline structure of PVDF, various contents of $\mathrm{SiC}$ nanowires were added into PVDF solution. The SiC nanowires were found to be well dispersed in the PVDF matrix as indicated by SEM image (Figure 3a). The morphology of $\mathrm{SiC}$ nanowire was clearly observed at higher magnification of SEM image (Figure 3b). The diameter of the nanowire was about $500 \mathrm{~nm}$. The optical microscope image showed the various lengths of $\mathrm{SiC}$ nanowires (Figure 3c). The thickness of PVDF/SiC film was about 25 30 um as measured by stylus profiler.

In the FT-IR spectra of pure PVDF and PVDF/SiC composites shown in Figure 4, the absorption band presented at $802 \mathrm{~cm}^{-1}$ is assigned to the stretching vibration peak of Si-C bond [33]. 

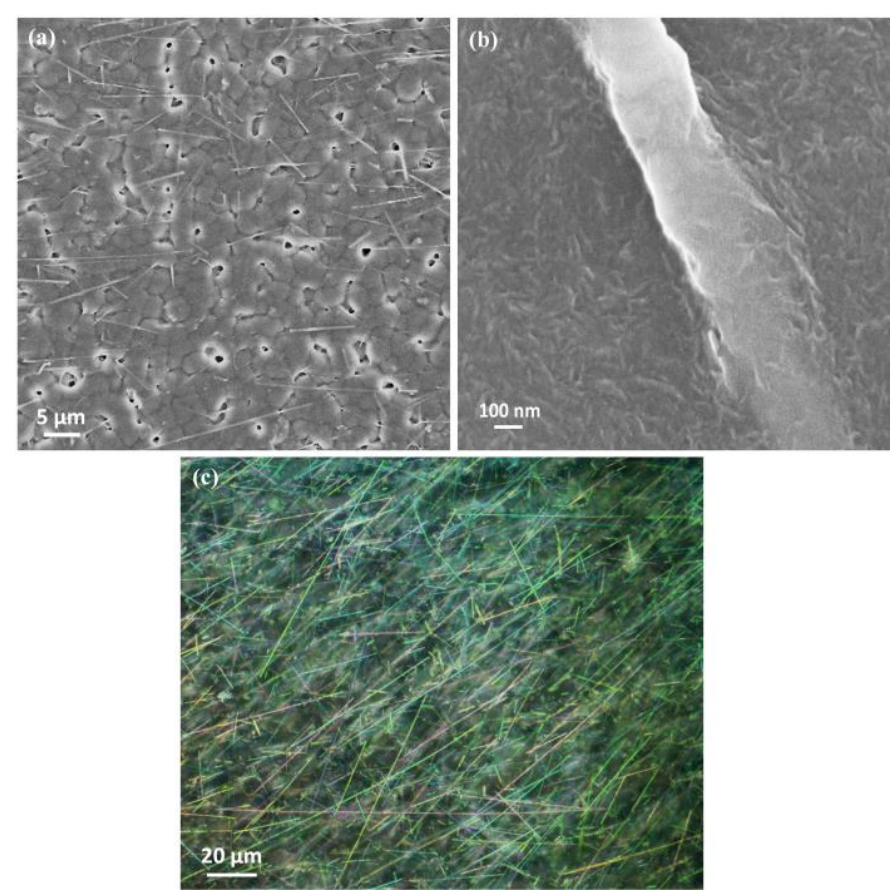

Figure 3. (a) Low magnified image of SEM shows SiC nanowires were well dispersed in the PVDF matrix; (b) High magnified image of SEM presents the diameter of $\mathrm{SiC}$ nanowires; (c) The image of optical microscope present the length of $\mathrm{SiC}$ nanowires.

When pure PVDF annealed at the temperature of $140^{\circ} \mathrm{C}$, the dominant crystalline form was $\alpha$ phase. However, with the addition of $\mathrm{SiC}$ nanowires, the characteristic bands of $\alpha$ phase significantly decreased and even disappeared at higher doping concentrations, as shown in Figure 4a. At the close overlapping of the characteristic band of $\mathrm{Si}-\mathrm{C}$ bond located at $802 \mathrm{~cm}^{-1}$ and the $\alpha$ phase located at $795 \mathrm{~cm}^{-1}$ in the spectra, the growing of absorption band at approximately $800 \mathrm{~cm}^{-1}$ is ascribed to the $\mathrm{Si}-\mathrm{C}$ bond with the increasing ratio of $\mathrm{PVDF} / \mathrm{SiC}$. In the meantime, the characteristic band of 840 $\mathrm{cm}^{-1}$ corresponding to the $\beta$ phase and the characteristic band of $1234 \mathrm{~cm}^{-1}$ corresponding to the $\gamma$ phase were enhanced distinctly. As for the PVDF samples annealed at $80^{\circ} \mathrm{C}, \beta$ phase was the domain crystalline phase of pure PVDF. After mixing with $\mathrm{SiC}$ nanowires, the characteristic band of $\gamma$ phases was enhanced, whereas the characteristic band of $\beta$ phase was almost intact (Figure 4 and their partial enlarged drawings at the upper right corner). However, the characteristic bands of $\alpha$ phase located at 764,976 , and $1210 \mathrm{~cm}^{-1}$ were almost disappeared completely. Therefore, the results of FT-IR spectra confirmed that $\mathrm{SiC}$ nanowires promoted the formation of polar phases of PVDF while depressing the formation of $\alpha$ phase.

\subsection{OVERALL CRYSTALLINITY AND PHASE CONTENT OF PURE PVDF AND PVDFISIC COMPOSITES}

As one of the two most common crystalline structures (nonpolar $\alpha$ phase and polar $\beta$ phase) of PVDF, the $\beta$ phase is of great importance in the applications of PVDF because of its pyro- and piezoelectric properties [34]. Therefore, increasing the
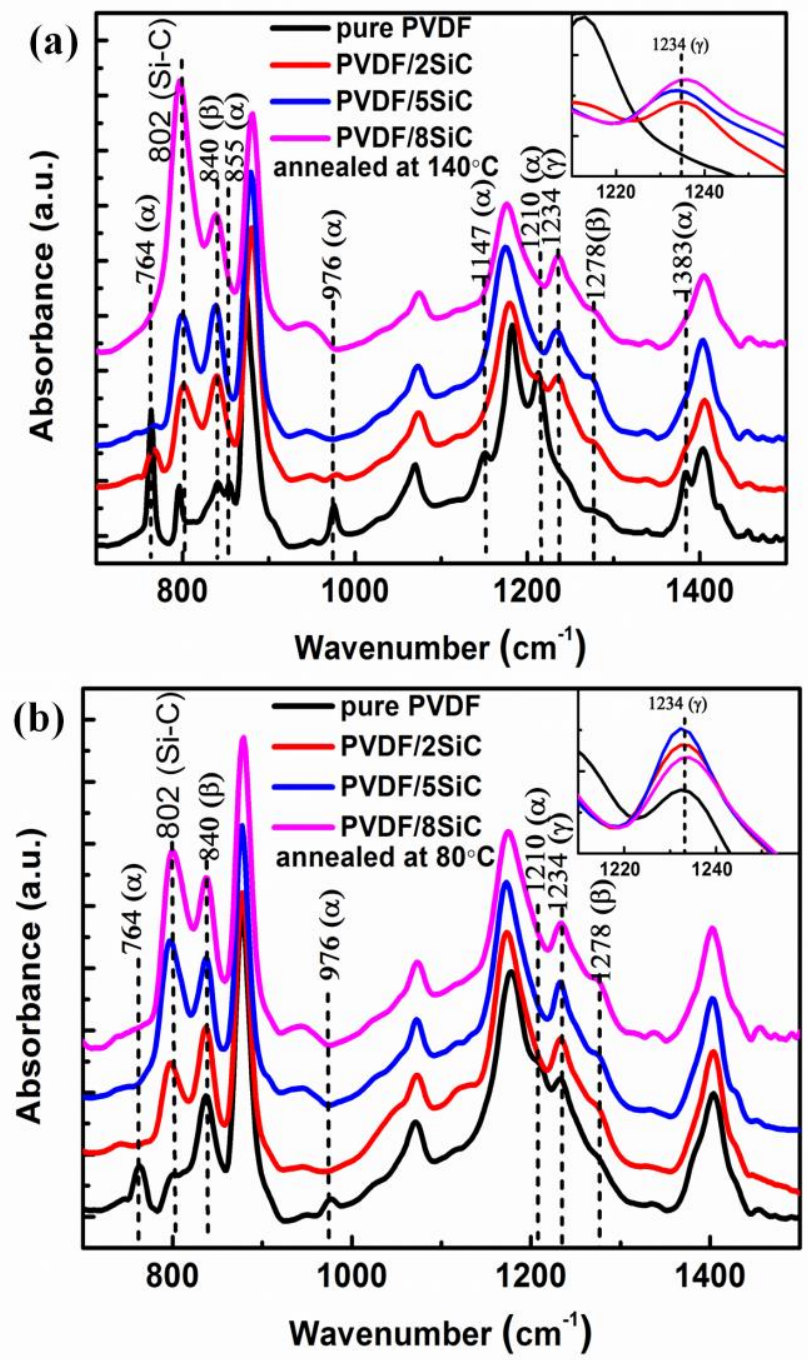

Figure 4. FT-IR spectra of pure PVDF and PVDF/SiC composites annealed at (a) $140^{\circ} \mathrm{C}$ and (b) $80^{\circ} \mathrm{C}$

relative fraction of $\beta$ phase is the key in improving the performances of PVDF polymer.

The overall crystallinity of the polymer can be obtained from the DSC thermograms. The samples were melted at $200^{\circ} \mathrm{C}$ for $10 \mathrm{~min}$ to erase the thermal history, then cooled from 200 to $20^{\circ} \mathrm{C}$ at a rate of $10^{\circ} \mathrm{C} / \mathrm{min}$, and heated from $20^{\circ} \mathrm{C}$ to $200^{\circ} \mathrm{C}$ at the same rate. The DSC measurement processing was performed in $\mathrm{N}_{2}$ atmosphere. The overall crystallinity of pure PVDF and $\mathrm{PVDF} / \mathrm{SiC}$ composite can be calculated using the following equation:

$$
\mathrm{X}_{\mathrm{c}}(\%)=\frac{\Delta \mathrm{H}_{\mathrm{m}}}{\Delta \mathrm{H}_{0}}
$$

where $\triangle \mathrm{H}_{\mathrm{m}}$ is the actual melting enthalpy of the sample, $\triangle \mathrm{H}_{0}$ is the melting enthalpy of $100 \%$ crystalline sample. The melting enthalpy of $100 \%$ crystalline PVDF is $104.6 \mathrm{~J} / \mathrm{g}$ [35]. The DSC results of pure PVDF and PVDF/SiC composite were shown in Table 1. As shown in Table 1, the overall crystallinity in $\mathrm{PVDF} / \mathrm{SiC}$ composites is less than the pure 
PVDF. This is due to the fact that in the process of transforming $\alpha$ phase into $\beta$ phase, the reduction in $\alpha$ phase crystallinity was more than the increase of $\beta$ phase crystallinity. This is clearly seen in the FT-IR spectra. The maximum $\mathrm{X}_{\mathrm{c}}$ was found to be $53.4 \%$ for pure PVDF sample, whose domain crystal was $\alpha$ phase. For the PVDF/SiC composites, the overall crystallinity $\mathrm{X}_{\mathrm{c}}$ increased with the increasing content of $\mathrm{SiC}$ nanowires. However, further measurement will need be taken for calculating the relative fraction of $\beta$ phase in the pure $\mathrm{PVDF}$ and $\mathrm{PVDF} / \mathrm{SiC}$ composites.

Table 1. Overall Crystallinity of pure PVDF and PVDF/SiC composites

\begin{tabular}{l|l|l}
\hline Samples & $\triangle \mathbf{H}_{\mathbf{m}}(\mathbf{J} / \mathbf{g})$ & $\mathbf{X}_{\mathbf{c}}(\%)$ \\
$\mathrm{PVDF}$ & 53.6 & 53.4 \\
$\mathrm{PVDF} / 2 \mathrm{SiC}$ & 46.0 & 45.8 \\
$\mathrm{PVDF} / 5 \mathrm{SiC}$ & 48.8 & 48.6 \\
$\mathrm{PVDF} / 8 \mathrm{SiC}$ & 49.2 & 49.0 \\
\hline
\end{tabular}

FT-IR spectra are commonly used to calculate the relative fraction of $\beta$ phase by quantifying the $\alpha$ and $\beta$ phases of PVDF at the characteristic absorption bands of 764 and $840 \mathrm{~cm}^{-1}$, which was explained by Gregorio [11-12, 19]. This method is based on the assumption that FT-IR absorption obeys the Lambert-Beer law, and it was used in multiple studies [11, 18, 23]. The absorption coefficients $K_{\alpha}$ and $K_{\beta}$ are calculated at the absorption bands of 764 and $840 \mathrm{~cm}^{-1}$. The relative fraction of $\beta$ phase in PVDF samples containing $\alpha$ and $\beta$ phases can be calculated using the following equation [12]:

$$
\mathrm{F}(\beta)=\frac{X_{\beta}}{X_{\alpha}+X_{\beta}}=\frac{A_{\beta}}{\left(K_{\beta} / K_{\alpha}\right) A_{\alpha}+A_{\beta}}=\frac{A_{\beta}}{1.26 A_{\alpha}+A_{\beta}}
$$

Where $F(\beta)$ is the relative $\beta$ phase content of the sample; $A_{\alpha}$ and $A_{\beta}$ represent the absorbance at the bands of 764 and 840 $\mathrm{cm}^{-1} ; \mathrm{K}_{\alpha}$ and $\mathrm{K}_{\beta}$ are the absorption coefficients at the corresponding wavenumber. The values of $\mathrm{K}_{\alpha}$ and $\mathrm{K}_{\beta}$ are $6.1 \times 10^{4}$ and $7.7 \times 10^{4} \mathrm{~cm}^{2} / \mathrm{mol}$, respectively [12].

For the $\mathrm{PVDF} / \mathrm{SiC}$ composites, the variation of the relative $\beta$ phase fraction as a function of the increasing content of $\mathrm{SiC}$ nanowires was shown in Figure 5. Generally, the relative fraction of $\beta$ phase firstly increases upon increasing the doping concentration of $\mathrm{SiC}$ nanowires, and then reaches a maximum value at certain concentration of $\mathrm{SiC}$ nanowires. This pattern was observed in both cases where the samples were annealed at $140{ }^{\circ} \mathrm{C}$ and $80{ }^{\circ} \mathrm{C}$, but showing different curve growing profiles and different optimized doping concentrations. For PVDF annealed at $140^{\circ} \mathrm{C}$, the relative crystalline fraction of $\beta$ phase was only $17 \%$. With the addition of $\mathrm{SiC}$ nanowires, the relative fraction of $\beta$ phase increased markedly and reached a maximum value of around $54 \%$ at the doping concentration of $5 \mathrm{wt} \%$. PVDF/SiC composite samples annealed at $80{ }^{\circ} \mathrm{C}$ presented higher relative fractions of $\beta$ phase than those annealed at $140{ }^{\circ} \mathrm{C}$ at the same doping $\mathrm{SiC}$ nanowire concentration. A maximum $\beta$ phase fraction of around $80 \%$ was seen in the sample with $2 \mathrm{wt} \% \mathrm{SiC}$ nanowire concentration and annealed at $80^{\circ} \mathrm{C}$. After the maximum value was reached, the relative fraction of $\beta$ phase began to reduce as the SiC doping concentration increased further, which coincided

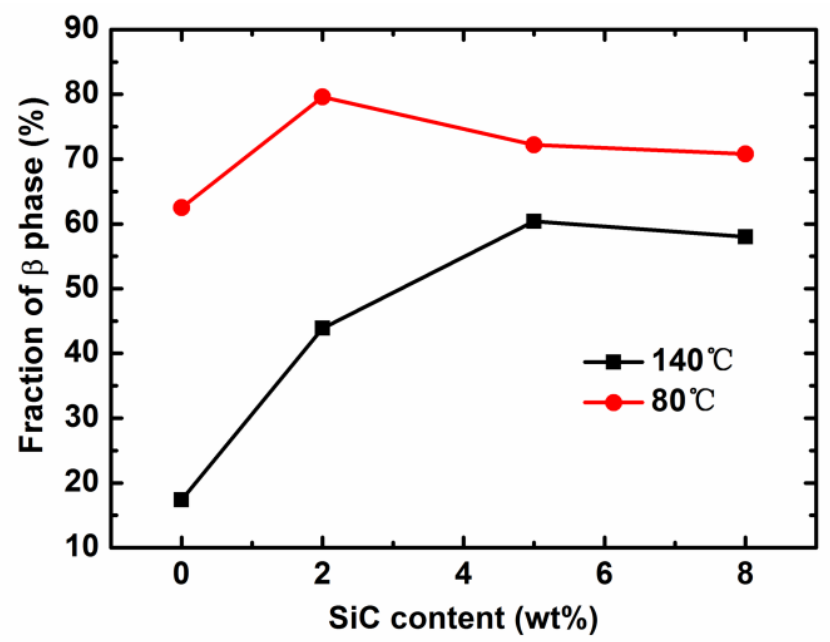

Figure 5. Relative fraction of $\beta$ phase with increasing $\mathrm{SiC}$ nanowires content.

with the results of $\mathrm{PVDF} / \mathrm{kaolinite}$ and $\mathrm{PVDF} / \mathrm{TDPA}-\mathrm{BaTiO}_{3}$ obtained by Thakur and Ye, respectively [18-19]. Obviously, mixing PVDF with $\mathrm{SiC}$ nanowires can improve the relative fraction of $\beta$ phase in the $\mathrm{PVDF} / \mathrm{SiC}$ composites, especially at the annealing temperature of $80^{\circ} \mathrm{C}$. Even for the pure PVDF that form little $\beta$ phase when annealed at $140^{\circ} \mathrm{C}$, adding certain value of $\mathrm{SiC}$ nanowires can substantially increase the relative fraction of $\beta$ phase.

\section{DISCUSSION}

FT-IR spectra indicates that the addition of $\mathrm{SiC}$ nanowires favors the formation of polar phases in PVDF. It is conceived that $\mathrm{SiC}$ nanowires can interact with PVDF molecules, facilitating the formation of polar phases and reducing the proportion of non-polar $\alpha$ phase. In order to explore the interacting mechanism between PVDF polymer and $\mathrm{SiC}$ nanowires, we investigated the surface of $\mathrm{SiC}$ nanowires. The surface of $\mathrm{SiC}$ nanowires can be easily oxidized and form a thin (1-2 nm) amorphous film which is mostly $\mathrm{SiO}_{2}$ [36]. To prove the existence of $\mathrm{SiO}_{2}$ in the $\mathrm{SiC}$ nanowires, energy dispersive spectroscope (EDS) tests were conducted to measure the chemical contents of the nanowires. In the EDS spectra of the raw $\mathrm{SiC}$ nanowires, the chemical element of carbon, oxygen, and silicon were detected with the weight percentage values of $15.38 \%, 0.78 \%$, and $83.84 \%$, respectively. It indicated that the surface of the $\mathrm{SiC}$ nanowires was oxidized and a thin $\mathrm{SiO}_{2}$ layer was formed. When $\mathrm{SiC}$ nanowires were dispersed in the reaction solution, the amorphous $\mathrm{SiO}_{2}$ thin films ( $\mathrm{Si}-\mathrm{O}-\mathrm{Si}$ bond) on the surface of $\mathrm{SiC}$ nanowire will hydrolyze and form the stable silanol ( $\mathrm{Si}$ $\mathrm{OH}$ ) films. The process of $\mathrm{SiO}_{2}$ hydrolysis reaction can be described by the chemical equation shown below:

$$
\mathrm{SiO}_{2}+\mathrm{H}_{2} \mathrm{O} \rightarrow \mathrm{SiOH}
$$

$\mathrm{SiOH}$ will generate positively charged $\left[\mathrm{SiOH}_{2}\right]^{+}$in acidic conditions and create negatively charged $\mathrm{SiO}^{-}$and water by dehydrogenation in alkaline environment, as following shown 
[37]:

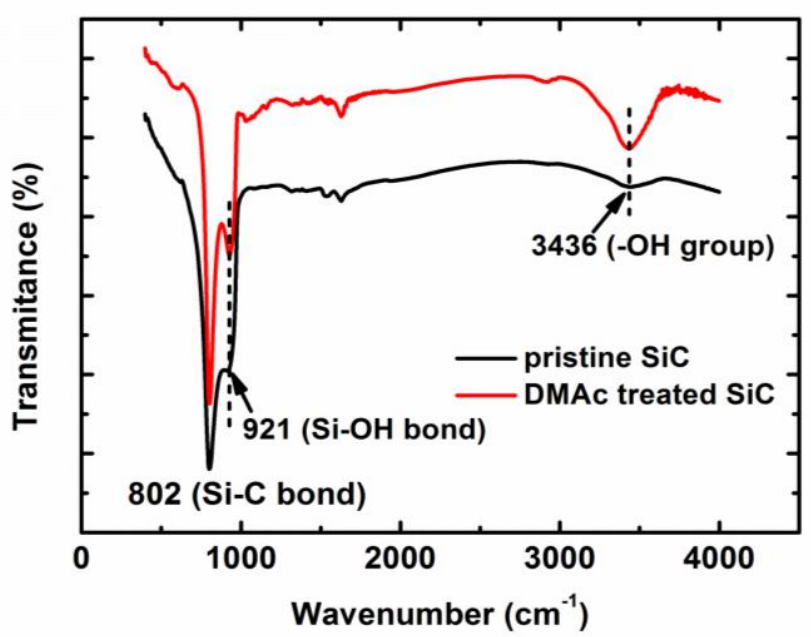

Figure 6. FT-IR spectra of pristine $\mathrm{SiC}$ nanowires and $\mathrm{SiC}$ nanowires treated with DMAc solution.

$$
\left[\mathrm{SiOH}_{2}\right]^{+} \stackrel{\mathrm{H}^{+}}{\longleftarrow}[\mathrm{SiOH}] \stackrel{\mathrm{OH}^{-}}{\longrightarrow}[\mathrm{SiO}]^{-}+\mathrm{H}_{2} \mathrm{O}
$$

The $\mathrm{pH}$ value of DMAc solvent used in the treatment solution was measured by the multi-parameter tester and its value was 10.11, which indicated that DMAc solution was alkaline. As shown in the FT-IR spectra of pristine $\mathrm{SiC}$ nanowires and $\mathrm{SiC}$ nanowires treated with DMAc (Figure 6), the characteristic bands at $921 \mathrm{~cm}^{-1}$ (Si-OH stretching) and $3436 \mathrm{~cm}^{-1}$ (-OH group) were enhanced, indicating that DMAc could facilitate the hydrolysis of $\mathrm{SiO}_{2}$ and form more $\mathrm{Si}-\mathrm{OH}$ bonds on the surface of $\mathrm{SiC}$ nanowire [38]. In alkaline conditions, the Si$\mathrm{OH}$ groups will transfer the proton $\left(\mathrm{H}^{+}\right)$to the basic species in the solvent, forming the anionic group $\mathrm{Si}_{-} \mathrm{O}^{-}$on the $\mathrm{SiC}$ nanowire surface [37], as shown in Figure 7b. Therefore, the surface of $\mathrm{SiC}$ nanowire was negatively charged. The negatively charged surface of $\mathrm{SiC}$ nanowires and the positive charge of $\mathrm{CH}_{2}$ groups of PVDF exhibited an affinity between

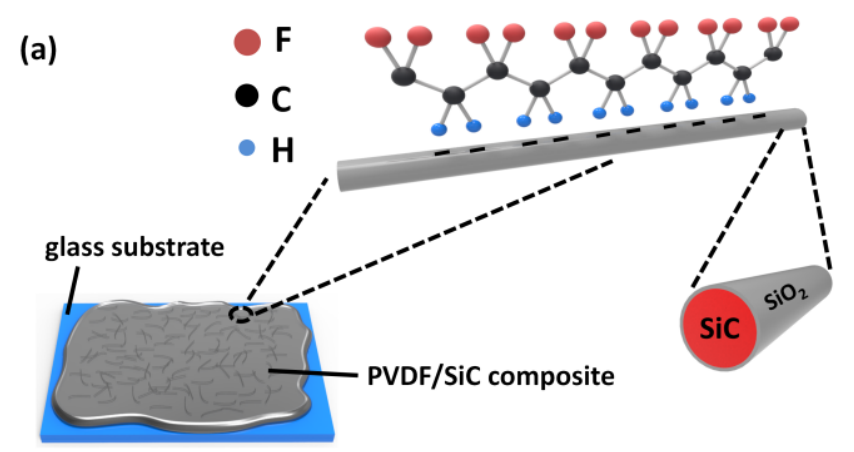

(b)

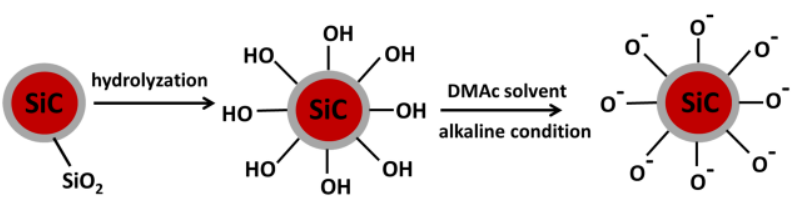

Figure 7. (a) Schematic representation of the interaction mechanism between PVDF polymer and SiC nanowires; (b) The flow chart of chemical reactions occur on the surface of $\mathrm{SiC}$ nanowire.

the $\mathrm{SiC}$ nanowires and PVDF. The ion-dipole interaction caused the polymer chains to align on the $\mathrm{SiC}$ nanowire surface, facilitating the preferential formation of $\beta$ and $\gamma$ phases chain conformation of PVDF, as shown in Figure 7a. The enhancement of $\beta$ phase crystallization of PVDF was attributed to the regular dipole orientation and PVDF molecular chain alignment along $\mathrm{SiC}$ nanowires in long-range order. Therefore, $\mathrm{SiC}$ nanowires acted as the nucleating agents and favored the formation of all-trans planar zigzag chain conformation of PVDF. Similar mechanisms were reported in the previous studies: the formation of $\beta$-PVDF with modified clay [23], kaolinite/halloysit [18], palladium nanoparticles [32], gold nanoparticle and gold nanoshell [39]. Due to the different extents of interaction force between the $\mathrm{CH}_{2}$ groups and negatively charged surface of $\mathrm{SiC}$ nanowires upon their distance, PVDF polymer may form $\beta$ phase in the vicinity of $\mathrm{SiC}$ nanowire, and form $\gamma$ phase with a slight distance away from the $\mathrm{SiC}$ nanowire.

\section{CONCLUSION}

In this work, pure PVDF and PVDF/SiC-nanowire composite films with different $\mathrm{SiC}$ doping concentrations of 2 $\mathrm{wt} \%, 5 \mathrm{wt} \%$, and $8 \mathrm{wt} \%$ were prepared by solution processing. The samples were annealed at $140^{\circ} \mathrm{C}$ and $80^{\circ} \mathrm{C}$, respectively, to investigate the phase and crystalline structures transformations of PVDF. Annealing temperature and $\mathrm{SiC}$ doping concentrations have significant effects on the phase types and phase fractions. The maximum relative fraction of $\beta$ phase in PVDF of about $54 \%$ was obtained at the doping $\mathrm{SiC}$ nanowire concentration of $5 \mathrm{wt} \%$ when the annealing temperature was $140^{\circ} \mathrm{C}$. As for the samples annealed at $80^{\circ} \mathrm{C}$, the $\beta$ phase presented higher fraction of about $80 \%$ at the $\mathrm{SiC}$ nanowire concentration of $2 \mathrm{wt} \%$. The electrostatic interaction between the $\mathrm{CH}_{2}$ dipoles of PVDF and negatively charged surface of $\mathrm{SiC}$ nanowires led to the change in dipole orientation. As a result, the molecular chains of PVDF orderly aligned along the $\mathrm{SiC}$ nanowires and the $\mathrm{CF}_{2}$ dipoles arranged in the direction perpendicular to the polymer chain, which favored the formation of polar phases, and could potentially improve the piezoelectric property of PVDF polymer.

\section{ACKNOWLEDGMENT}

This work was financially supported by the projects from the National High Technology Research and Development Program of China (863 Project) (2015AA033408), the National Natural Science Foundation of China (61307027), the Science and Technology Program of Guangdong Province (2014-B090914001), and Shunde Government, Guangdong Province, China (20140401). 


\section{REFERENCES}

[1] A. Kimoto, N. Sugitani, and S. Fujisaki, "A Multifunctional Tactile Sensor Based on PVDF Films for Identification of Materials," IEEE Sens. J., Vol. 10, No. 9, pp. 1508-1513, Sep, 2010.

[2] T. Sharma, S. Naik, J. Langevine, B. Gill, and J. X. J. Zhang, "Aligned PVDF-TrFE Nanofibers With High-Density PVDF Nanofibers and PVDF Core-Shell Structures for Endovascular Pressure Sensing," IEEE T. Bio-med Eng., Vol. 62, No. 1, pp. 188-195, Jan, 2015.

[3] V. Bhavanasi, V. Kumar, K. Parida, J. X. Wang, and P. S. Lee, "Enhanced Piezoelectric Energy Harvesting Performance of Flexible PVDF-TrFE Bilayer Films with Graphene Oxide," Acs Appl. Mater. Inter., Vol. 8, No. 1, pp. 521-529, Jan 13, 2016.

[4] B. Y. Ren, and C. J. Lissenden, "PVDF Multielement Lamb Wave Sensor for Structural Health Monitoring," IEEE T. Ultrason. Ferr., Vol. 63, No. 1, pp. 178-185, Jan, 2016.

[5] D. H. Wang, and S. L. Huang, "Health monitoring and diagnosis for flexible structures with PVDF piezoelectric film sensor array," J. of Intell. Mat. Sys. Str., Vol. 11, No. 6, pp. 482-491, Jun, 2000.

[6] A. J. Lovinger, "Annealing of poly(vinylidene fluoride) and formation of a fifth phase," Macromolecules, Vol. 15, No. 1, pp. 40-44, 1982.

[7] M. Benz, and W. B. Euler, "Determination of the crystalline phases of poly(vinylidene fluoride) under different preparation conditions using differential scanning calorimetry and infrared spectroscopy," J. Appl. Polym. Sci., Vol. 89, No. 4, pp. 1093-1100, Jul 25, 2003.

[8] K. Sakaoku, and A. Peterlin, "Poly(vinylidene fluoride) single crystals," J. of Macromol. Sci. B, Vol. 1, No. 2, pp. 401-406, 1967.

[9] K. Okuda, T. Yoshida, M. Sugita, and M. Asahina, "Solution-grown crystals of poly(vinylidene fluoride)," J. Polym. Sci. Polym. Lett., Vol. 5, No. 6, pp. 465-468, 1967.

[10] P. Martins, A. C. Lopes, and S. Lanceros-Mendez, "Electroactive phases of poly(vinylidene fluoride): Determination, processing and applications," Progr. Polym. Sci., Vol. 39, No. 4, pp. 683-706, Apr, 2014.

[11] J. Gomes, J. Serrado Nunes, V. Sencadas, and S. Lanceros-Mendez, "Influence of the $\beta$-phase content and degree of crystallinity on the piezo- and ferroelectric properties of poly(vinylidene fluoride)," Smart Mater. Struct., Vol. 19, No. 6, pp. 065010, 2010.

[12] J. R. Gregorio, and M. Cestari, "Effect of crystallization temperature on the crystalline phase content and morphology of poly(vinylidene fluoride)," J. Polym. Sci. Pol. Phys., Vol. 32, No. 5, pp. 859-870, 1994.

[13] G. T. Davis, J. E. McKinney, M. G. Broadhurst, and S. C. Roth, "Electric-field-induced phase changes in poly(vinylidene fluoride)," J. Appl. Phys., Vol. 49, No. 10, pp. 4998, 1978.

[14] J. F. Zheng, A. H. He, J. X. Li, and C. C. Han, "Polymorphism control of poly(vinylidene fluoride) through electrospinning," Macromol. Rapid Comm., Vol. 28, No. 22, pp. 2159-2162, Nov 16, 2007.

[15] G. Y. Ren, F. Y. Cai, B. Z. Li, J. M. Zheng, and C. Y. Xu, "Flexible Pressure Sensor Based on a Poly(VDF-TrFE) Nanofiber Web," Macromol. Mater. and Eng., Vol. 298, No. 5, pp. 541-546, May, 2013.

[16] A. Salimi, and A. A. Yousefi, "Conformational changes and phase transformation mechanisms in PVDF solution-cast films," J. Polym. Sci. Pol. Phys., Vol. 42, No. 18, pp. 3487-3495, 2004.

[17] A. P. Indolia, and M. S. Gaur, "Investigation of structural and thermal characteristics of PVDF/ZnO nanocomposites," J. Therm. Anal. Calorim., Vol. 113, No. 2, pp. 821-830, 2012.

[18] P. Thakur, A. Kool, B. Bagchi, S. Das, and P. Nandy, "Enhancement of beta phase crystallization and dielectric behavior of kaolinite/halloysite modified poly(vinylidene fluoride) thin films," Appl. Clay Sci., Vol. 99, pp. 149-159, Sep, 2014.

[19] H. J. Ye, W. Z. Shao, and L. Zhen, "Crystallization kinetics and phase transformation of poly(vinylidene fluoride) films incorporated with functionalized baTiO3 nanoparticles," J. Appl. Polym. Sci., Vol. 129, No. 5, pp. 2940-2949, Sep 5, 2013.

[20] P. Martins, X. Moya, L. C. Phillips, S. Kar-Narayan, N. D. Mathur, and S. Lanceros-Mendez, "Linear anhysteretic direct magnetoelectric effect in $\mathrm{Ni} 0.5 \mathrm{Zn} 0.5 \mathrm{Fe} 2 \mathrm{O} 4 / \mathrm{poly}$ (vinylidene fluoride-trifluoroethylene) 0-3 nanocomposites," J. Phys. D Appl. Phys., Vol. 44, No. 48, pp. 482001, 2011.

[21] W. Wang, S. Zhang, L.-o. Srisombat, T. R. Lee, and R. C. Advincula, "Gold-Nanoparticle- and Gold-Nanoshell-Induced Polymorphism in
Poly(vinylidene fluoride)," Macromol. Mater. Eng., Vol. 296, No. 2, pp. 178-184, 2011.

[22] N. L. An, H. Z. Liu, Y. C. Ding, M. Zhang, and Y. P. Tang, "Preparation and electroactive properties of a PVDF/nano-TiO2 composite film,” Appl. Surf. Sci., Vol. 257, No. 9, pp. 3831-3835, Feb $15,2011$.

[23] T. U. Patro, M. V. Mhalgi, D. V. Khakhar, and A. Misra, "Studies on poly(vinylidene fluoride)-clay nanocomposites: Effect of different clay modifiers," Polymer, Vol. 49, No. 16, pp. 3486-3499, 2008.

[24] G. W. Ho, A. S. W. Wong, D.-J. Kang, and M. E. Welland, "Threedimensional crystalline SiC nanowire flowers," Nanotechnology, Vol. 15, No. 8, pp. 996-999, 2004.

[25] J. Sheth, D. Kumar, V. K. Tiwari, and P. Maiti, "Silicon carbideinduced piezoelectric beta-phase in poly(vinylidene fluoride) and its properties," J. Mater. Res., Vol. 27, No. 14, pp. 1838-1845, Jul, 2012.

[26] R. Gregorio, "Determination of the alpha, beta, and gamma crystalline phases of poly(vinylidene fluoride) films prepared at different conditions," J. Appl. Polym. Sci., Vol. 100, No. 4, pp. 3272-3279, May $15,2006$.

[27] D. M. Esterly, and B. J. Love, "Phase transformation to betapoly(vinylidene fluoride) by milling," J. Polym. Sci. .Pol. Phys., Vol. 42, No. 1, pp. 91-97, Jan 1, 2004.

[28] J. S. Lee, A. A. Prabu, and K. J. Kim, "Annealing effect upon chain orientation, crystalline morphology, and polarizability of ultra-thin $\mathrm{P}(\mathrm{VDF}-\mathrm{TrFE})$ film for nonvolatile polymer memory device," Polymer, Vol. 51, No. 26, pp. 6319-6333, Dec 10, 2010.

[29] D. Mandal, S. Yoon, and K. J. Kim, "Origin of Piezoelectricity in an Electrospun Poly(vinylidene fluoride-trifluoroethylene) Nanofiber WebBased Nanogenerator and Nano-Pressure Sensor," Macromol. Rapid Comm., Vol. 32, No. 11, pp. 831-837, Jun 1, 2011.

[30] K. Tashiro, and M. Hanesaka, "Confirmation of crystal structure of poly (vinylidene fluoride) through the detailed structure analysis of vinylidene fluoride oligomers separated by supercritical fluid chromatography," Macromolecules, Vol. 75, No. 3, pp. 714-721, 2002.

[31] T. C. Hsu, and P. H. Geil, "Deformation and transformation mechanisms of poly (vinylidene fluoride)(PVF2)," J. Mater. Sci., Vol. 24, No. 4, pp. 1219-1232, 1989.

[32] D. Mandal, K. J. Kim, and J. S. Lee, "Simple synthesis of palladium nanoparticles, beta-phase formation, and the control of chain and dipole orientations in palladium-doped poly(vinylidene fluoride) thin films," Langmuir, Vol. 28, No. 28, pp. 10310-7, Jul 17, 2012.

[33] Y. C. Li, and S. C. Tjong, "Structure and Electrical Characteristics of Poly(vinylidene fluoride) Filled with Beta Silicon Carbide Nanoparticles," J. Nanosci. and Nanotechno., Vol. 11, No. 6, pp. 51485153, Jun, 2011.

[34] F. Liu, R. Huo, X. Huang, Q. Lei, and P. Jiang, "Crystalline properties, dielectric response and thermal stability of in-situ reduced graphene oxide/poly(vinylidene fluoride) nanocomposites," IEEE Trans. Dielectri. Electr. Insul., Vol. 21, No. 4, pp. 1446-1454, 2014.

[35] G. Teyssedre, A. Bernes, and C. Lacabanne, "Influence of the crystalline phase on the molecular mobility of PVDF," J. Polym. Sci. Pol. Phys., Vol. 31, No. 13, pp. 2027-2034, 1993.

[36] S. Novak, J. Kovač, G. Dražić, J. M. F. Ferreira, and S. Quaresma, "Surface characterisation and modification of submicron and nanosized silicon carbide powders," J. Eur. Ceram. Soc., Vol. 27, No. 12, pp. 3545-3550, 2007.

[37] Q. Huang, P. Chen, M. Y. Gu, Y. P. Jin, and K. Sun, "Effect of surface modification on the rheological behavior of concentrated, aqueous $\mathrm{SiC}$ suspensions," Mater. Lett., Vol. 56, No. 4, pp. 546-553, Oct, 2002.

[38] D. S. Kim, H. B. Park, J. W. Rhim, and Y. M. Lee, "Proton conductivity and methanol transport behavior of cross-linked PVA/PAA/silica hybrid membranes," Solid State Ionics, Vol. 176, No. 1-2, pp. 117-126, Jan 14, 2005.

[39] W. Wang, S. Zhang, L. O. Srisombat, T. R. Lee, and R. C. Advincula,. "Gold-Nanoparticle- and Gold-Nanoshell- Induced Polymorphism in Poly (vinylidene fluoride)," Macromol. Mater. Eng., Vol. 296, No. 2, pp. 178-184, 2011. 


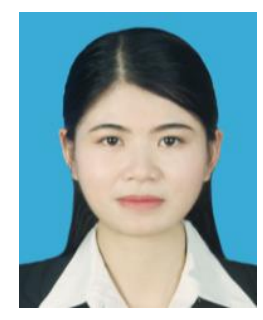

pressure sensor.
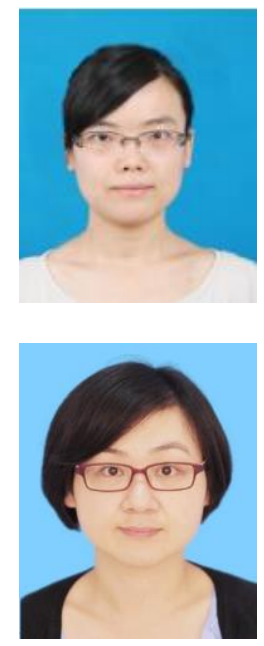

Jie-Fang Huang received the B.S. degree in Microelectronics from the School of Physics and Engineering, Sun Yat-Sen University, Guangzhou, China, in 2014. She has researched on self-powered electronics based on piezoelectricity and triboelectricity in the State Key Laboratory of Optoelectronic Materials and Technologies since 2013. Miss Huang is pursuing her master degree in the major of Microelectronics and Solid-State Electronics now, focusing on flexible and wearable

Song-Jia Han received the B.S. degree in school of materials science and engineering from Wuhan University of Technology, Wuhan, China, in 2010 and the M.S. degree in college of polymer science and engineering from Sichuan University, Chengdu, China, in 2013.Since 2013, she joined Sun Yat-Sen University, as a research assistant, researching on the development of the transparent conductive films and piezoelectric sensor.

Hui-Jiuan Chen received the B.S. degree in clinical medicine from Fujian Medical University, Fuzhou, China, in 2006 and the M.S. degree in biomedical engineering from Queen Mary University of London, London, UK, in 2009 as well as the Ph.D. degree in material science at Queen Mary University of London, London, UK, in 2013. Since 2013, she has been an Associate Research Fellow with the SYSUCMU Shunde International Joint Research Institute. She has published more than 10 articles. Her research interest includes applying nanoparticles in the biomedical direction, covering a wide spectrum of nanotechnology, medicine and engineering science, centered on preparations and applications of nanomaterials, such as, flexible device, various thermal therapies. Dr. Chen's award includes Third Prize for the Best Oral Presentation, 17th CSCST-SCI conference, 2011.

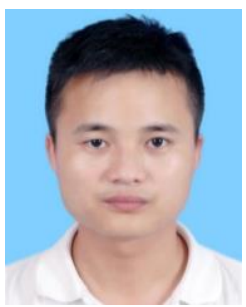

Gui-Shi Liu received the B.S. degree in applied physics from the East China Institute of Technology, Nanchang, China, in 2008 and the M.S. degree in plasma physics from Dalian University of Technology, Dalian, China, in 2011. He is currently working toward the Ph.D. degree in microelectronics and solid state electronics at Sun Yat-Sen University, Guangzhou, China. His research interests include patterning, transfer printing of silver nanowires for sensors.

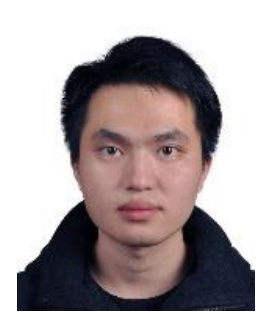

Gong-Tan Li received his B.S. degree in material physics from the School of Physics and Engineering, Sun Yat-Sen University, Guangzhou, China, in 2011. Since Sep. 2011, he was working for Ph. D degree in the major of the microelectronics, researching on oxide thin film transistors in the State Key Laboratory of Optoelectronic Materials and Technologies.

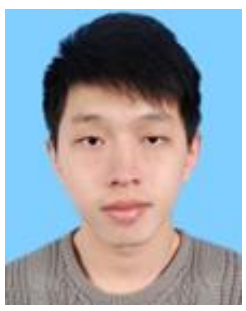

Yu-Cheng Wang received the B.S. degree in Information Display \& Optoelectronics technology from the School of Physics and Engineering, Sun Yat-Sen University, Guangzhou, China, in 2015. He is now a graduate student in the major of Microelectronics and

Solid-State Electronics, researching on e-paper display and self-power electronics in the State Key Laboratory of Optoelectronic Materials and Technologies.
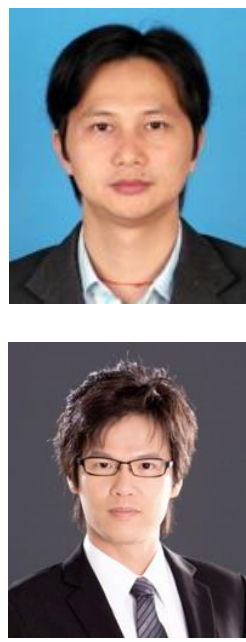

Zi-Xin Wang received his B.Sc. degree in Physics, M.S. and Ph.D. degrees in Optical engineering from Sun Yet-Sen University, in 1999, 2002, and 2006, respectively. In 2006, he joined the Department of Microelectronics at Sun Yat-Sen University, as an assistant professor. His specific research interests are low noise electronic techniques, lock-in amplification system, mixed-signal and high level synthesis. He is currently an associate professor.

Bo-Ru (Paul) Yang received his B.S. and M.S. degrees in Department of Material Science and Engineering from National Chiao Tung University (NCTU), Taiwan, in 2002 and National Tsing Hua University, Taiwan, in 2004, respectively. In 2008, he received his $\mathrm{Ph} . \mathrm{D}$. in Institute of Electro-Optical Engineering from NCTU, Taiwan, where he also finished an MBA program simultaneously. During his time studying Ph.D., he received the scholarships to study fast-switching LCD at University of Oxford, UK in 2007 and Tohoku University, JP in 2008 as a doctoral researcher. He was working with SiPixEink during 2009-2012. Since Dec. 2012, he joined Sun Yat-Sen University, China, as an associate professor, researching on the flexible electronics and displays. He is also an associate editor of Journal of Society for Information Display, JSID, and vice chair of flexible display and E-paper committee in SID 2017.

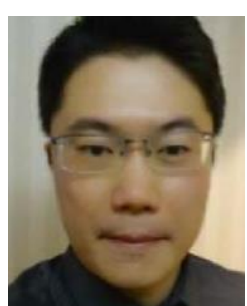

Zhen-Hua Luo received the B.Sc. degree in Nanotechnology in 2006, and the Ph.D. degree in 2011 from the University of New South Wales, Australia. His Ph.D. research was studying the PZT and lead-free piezoelectric ceramics. In 2009 he was working as a visiting researcher in the Technical University of Darmstadt, Germany, to research the lead-free piezoelectric ceramics including BNT-BT and KNN. In 2012 and 2013 he worked as a R\&D manager in a LED manufacturing company to develop energy harvesting floor. He joined the University of Southampton, UK, in 2013, currently working as a research fellow in EPSRC funded SPHERE project to develop energy harvesting solutions for residential sensing environment. His research interests include piezoelectric and solar energy harvesting, advanced piezoelectric materials and nanofabrication.

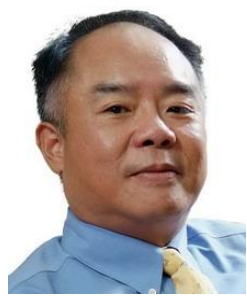

Han-Ping D. Shieh received the B.S. degree from National Taiwan University in 1975 and Ph.D. in electrical and computer engineering from Carnegie Mellon University, Pittsburgh, PA, U.S.A. in 1987. He joined National Chiao Tung University (NCTU) in Hsinchu, Taiwan as a professor at Institute of Opto-Electronic Engineering and Microelectronics and Information Research Center (MIRC) in 1992 after as a Research Staff Member at IBM TJ Watson Research Center, Yorktown Heights, NY, USA since 1988. He founded and served as the Director, Display Institute at NCTU in 2003, the first such kind of graduate academic institute in the world dedicated for display education and research. He was the Dean, College of Electrical and Computer Engineering, NCTU (2006-2010) and AU Optronics Chair Professor. He is now an NCTU Chair Professor and a NCTU senior vice President. He is also holding an appointment as a Chang Jiang Scholar at Shanghai Jiao Tong University since 2010. Dr. Shieh is a fellow of IEEE, OSA and SID (Society for Information Display). 